\title{
Escala de Interação com Pares: construção e evidências de validade para estudantes do ensino superior
}

\author{
Camila Alves Fiorr - Pontifícia Universidade Católica de Minas Gerais, Poços de \\ Caldas, Brasil \\ Elizabeth Mercuri - Universidade Estadual de Campinas, Campinas, Brasil \\ Leandro da Silva Almeida - Universidade do Minho, Braga, Portugal
}

\begin{abstract}
Resumo
As relações que os estudantes estabelecem com os pares são importantes para a aprendizagem e o desenvolvimento psicossocial e cognitivo. Diante disto, este estudo apresenta a construção e as evidências de validade da Escala de Interação com Pares para estudantes do ensino superior. Participaram da pesquisa 1070 universitários, com idade média de 23 anos $(\mathrm{DP}=6,5)$. A análise fatorial exploratória indicou uma estrutura multidimensional, composta pelos fatores: Interações Sociais, Interações Íntimas, Interações Acadêmicas pautadas no oferecimento de ajuda e Interações Acadêmicas com ênfase no recebimento de ajuda. A análise fatorial confirmatória destacou a adequação dos dados à estrutura fatorial $(\mathrm{CFI}=0,978$; GFI=0,980; RMSEA=0,06). Os coeficientes de regressão dos itens junto aos fatores foram satisfatórios $(0,55<\beta<0,86)$ e os indicadores de consistência interna de cada fator são adequados $(0,72<\boldsymbol{\alpha}<0,85)$. Tais resultados sinalizam a existência de propriedades psicométricas aceitáveis e sugerem eficiência na utilização do instrumento.

Palavras-chave: Estudante universitário, Universidade, Relações interpessoais, Construção de instrumento, Análise fatorial confirmatória.
\end{abstract}

Pair Interaction Scale: construction and evidence of validity for higher education students

\begin{abstract}
The relationships that students establish with pairs are important to their learning and to their psychosocial and cognitive development. In view of this, this study presents the construction and evidence of the validity of the Pair Interaction Scale for higher education students. 1070 university students with an average of 23 years of age $(S D=6.5)$ participated in the research. The exploratory factor analysis indicated a multidimensional structure, composed of the factors: Social Interactions, Intimate Interactions, Academic Interactions related to offering help and Academic Interactions with emphasis on receiving help. The confirmatory factor analysis highlighted the suitability of the data to the factor structure $(\mathrm{CFI}=0.978$; GFI=0.980; RMSEA=0.06). The regression coefficients of the items in relation to the factors were satisfactory $(0.55<\beta<0.86)$ and the indicators of internal consistency of each factor are suitable $(0.72<\boldsymbol{\alpha}<0.85)$. Such results signal the existence of acceptable psychometric parameters and efficiency in the utilization of the instrument is suggested.

Keywords: University student, University, Interpersonal relationships, Instrument construction, Confirmatory factor analysis.
\end{abstract}

A vida do ser humano é caracterizada pelo convívio social, o qual é imprescindível para o seu processo de socialização, aprendizado e desenvolvimento (Vygotsky, 2007). A partir do convívio social e da participação em grupos é que se constrói a rede social do indivíduo. Rede social, de acordo com Sluzki (1997), representa o conjunto de todas as relações significativas que o indivíduo estabelece com os outros, sendo a família a primeira delas. Uma das principais funções da rede social é o fornecimento do apoio social (Zanini, Verolla-Moutra \& Queiroz, 2009). Sabe-se, entretanto, que a rede social se modifica de acordo com as transformações inerentes

\footnotetext{
${ }^{1}$ Endereço para correspondência:

Rua Hermínia Aliberti, n.99 apto13 - Boa Vista

CEP: $13486-130$ - Limeira/SP

E-mail: cfior@hotmail.com
}

ao desenvolvimento humano e as transições vividas (Sluzki, 1997).

A passagem do ensino médio para o superior representa para o estudante uma dessas transições. Segundo Almeida, Soares e Ferreira (2000) essa passagem exige dos jovens a superação de desafios relacionados aos domínios acadêmicos, pessoais, vocacionais e sociais. Sob esse último aspecto, os estudantes necessitam construir um novo arranjo social, incluindo os vínculos interpessoais com amigos e colegas da universidade, que neste estudo são denominados pares. Sobre a presença das relações interpessoais no ensino superior, Ferreira, Medeiros e Pinheiro (1997) acrescentam que "o período de freqüência universitária, ao mesmo tempo que promove as relações interpessoais, possibilita, necessariamente, que as amizades se fortaleçam" (p. 152). 
Há algumas décadas, Feldman e Newcomb (1976), a partir de uma extensa revisão de literatura de mais de 1500 estudos sobre a influência do ensino superior no desenvolvimento do estudante, destacaram o papel das experiências de socialização que ocorrem entre os estudantes e seus pares. Coerente com as colocações acima, mas algumas décadas posteriores, Chickering e Reisser (1993) afirmaram que o professor mais importante do universitário é o outro estudante. Complementam, ainda, que a força da amizade e do grupo de referência é ampliada à medida que aumentam a frequência e a intensidade do contato entre os pares. Os autores enfatizam que "as relações são laboratórios para o estudante aprender a se comunicar, argumentar e refletir" (Chickering \& Reisser, 1993, p. 392). Além disso, o grupo de amigos que o estudante possui dentro da instituição faz a mediação entre o impacto das experiências universitárias e o desenvolvimento vivenciado pelos mesmos (Pascarella, 1985; Pike \& Kuh, 2006). Isso acontece porque "o conjunto de amigos dos estudantes pode ser importante em reforçar os valores e as atitudes dos alunos tão bem como em conduzi-los para mudanças nesses" (Feldman \& Newcomb, 1976, p. 243).

Longe de menosprezar o papel da relação professor-aluno no processo educativo, Bariani e Pavani (2008) assinalam a importância das interações entre os pares na formação do estudante. Estudos empíricos destacam que as interações com os pares são associadas a um conjunto de mudanças e desenvolvimento no estudante que envolvem aspectos cognitivos, afetivos e sociais (Astin, 1993; Carini, Kuh \& Klein, 2006; Kuh, 1995; Pascarella \& Terenzini, 2005; Pike \& Kuh, 2006; Terenzini, Pascarella \& Blimling, 1996; Whitt, Edson, Pascarella, Nora \& Terenzini, 1999). Tais autores pontuam, dentre as mudanças positivas vivenciadas pelos estudantes, alterações envolvendo habilidades analíticas, de resolução de problemas, de leitura e escrita, ampliação no entendimento sobre ciência, autoconhecimento, entre outras.

No âmbito nacional, Fior e Mercuri (2003) descrevem o envolvimento de universitários com atividades de natureza não obrigatória e que possibilitam uma ampliação no contato com os pares. Ainda segundo as autoras, os universitários percebem o conjunto de mudanças nos aspectos acadêmicos, sociais e pessoais como decorrentes das interações que estabelecem com os pares, o que sugere que $o$ envolvimento com os colegas é importante pela extensão e diversidade de alterações pessoais que proporciona. Contudo, nem sempre as mudanças associadas a tais interações correspondem a aspectos positivos. No geral, as experiências que envolvem conteúdos acadêmicos, como atividades de monitorias e estudo em grupo, são associadas a mudanças positivas. Por outro lado, dispêndio de tempo em tarefas sociais, como festas, relaciona-se de maneira negativa com o desenvolvimento cognitivo e o rendimento acadêmico dos universitários (Astin, 1993).

Terenzini e cols. (1996) sinalizam que a influência dos pares não depende simplesmente da ocorrência deste contato, mas do conteúdo das interações. Os autores destacam que "a evidência é geralmente clara que quando interações com pares envolvem atividades ou tópicos educacionais ou intelectuais, os efeitos são quase sempre benéficos ao estudante" (Terenzini \& cols., 1996, p. 156). Além disso, Whitt \& cols. (1999) sugerem que quando o conteúdo das interações está restrito à interação social, não envolvendo aspectos acadêmicos, o impacto pode não ser positivo para o desenvolvimento cognitivo e seu desempenho escolar. Porém, os achados de Kuh (1995), através da análise das atividades realizadas fora da sala de aula, reafirmam a contribuição das interações sociais para as mudanças vividas pelo estudante, incluindo alterações positivas nos aspectos sociais e afetivos. Estes resultados sugerem que os universitários interagem de maneira distinta com os colegas, sendo o conteúdo das interações uma das variáveis mediadoras entre a vivência dos relacionamentos interpessoais e o impacto que as mesmas têm na formação do universitário.

Para se compreender o conteúdo das interações que os estudantes estabelecem com os pares, retoma-se a proposta de Tinto (1997) para a análise da evasão. Segundo o autor, na vivência universitária o aluno se envolve com experiências relacionadas aos sistemas acadêmico e social da instituição. De acordo com Tinto (1997), são nesses sistemas, que incluem as aulas, laboratórios, bibliotecas e organizações estudantis, entre outros, que o estudante tem a oportunidade de interagir com pares e professores. Assim, considerando que os estudantes se envolvem nestes dois sistemas, as interações estabelecidas com os pares podem manifestar conteúdo acadêmico ou social.

No presente estudo, entende-se por interações acadêmicas o conjunto de atividades desenvolvidas pelos estudantes junto aos seus pares, que envolvem aspectos que se relacionam ao desenvolvimento e/ou cumprimento das exigências e tarefas do curso superior. Neste grupo estão incluídas interações como estudar em grupo, discutir tópicos do curso, realizar trabalhos em grupo, buscar ajuda de colegas para a resolução de problemas ligados ao estudo, ensinar ou aprender com outros estudantes, trabalhar em conjunto na realização de um projeto de pesquisa, buscar 
anotações de colegas. Já as interações com os pares que envolvem conteúdos sociais são entendidas como as ações desenvolvidas pelos estudantes com seus pares e que envolvem conteúdos característicos do convívio social do corpo discente de uma universidade. Dentre essas interações incluem-se aquelas relacionadas ao buscar ajuda dos pares para resolver um problema pessoal, auxiliar alunos com dificuldades, socializar-se com colegas, desenvolver atividades de lazer com outros estudantes, conversar e discutir questões envolvendo artes e música, socializar com estudantes de etnias e culturas distintas.

Ainda sobre as interações com pares, Pascarella (1985), na busca pela compreensão do processo de aprendizagem e desenvolvimento dos estudantes, acrescentou que as mesmas são fundamentais nesse processo. Engstrom e Tinto (2008) também sinalizam a importância da dimensão interativa no processo de permanência do aluno no ensino superior. Mas, deve-se ressaltar que não é apenas a presença ou ausência de interações que influenciam o desenvolvimento do estudante, inclusive sua aprendizagem; o conteúdo das interações tem sido apontado como um dos elementos importantes na explicação de diversas ocorrências. Neste sentido, o conteúdo das interações torna-se uma das principais características a serem analisadas no que tange às relações que os estudantes estabelecem com seus pares e abre uma nova possibilidade no estudo das relações interpessoais, não se pautando apenas na identificação de quem são as pessoas com as quais os estudantes se relacionam, mas tendo como foco o conteúdo acadêmico ou social das interações.

Assim, é consenso na literatura a necessidade de se conhecer aspectos particulares do desenvolvimento psicossocial de alunos do ensino superior, como as interações estabelecidas com os colegas, a fim de favorecer práticas que contribuam para a formação dos estudantes. Com o intuito de propor ferramentas auxiliares para a realização de diagnósticos que subsidiem atuações voltadas à promoção do bem-estar e do sucesso acadêmico dos alunos, a construção de instrumentos de avaliação torna-se caminho indispensável.

A partir destas colocações, este artigo apresenta o processo de construção e validação de um instrumento útil para avaliar o conteúdo das interações que os estudantes estabelecem com os pares, denominado Escala de Interação com os Pares.

\section{Método}

\section{Participantes}

Compuseram a amostra deste estudo 1070 estudantes de ensino superior, matriculados em uma das maiores universidades confessionais do país, localizada na região Sudeste. $\mathrm{Na}$ seleção dos participantes buscou-se uma heterogeneidade na amostra. Do total, $535(50 \%)$ dos estudantes era do sexo feminino. A faixa etária dos participantes variou de 17 a 69 anos ( $M=23$ anos; $\mathrm{DP}=5,6$ anos) e os mesmos estavam matriculados em momentos distintos do curso, sendo que 586 (54,7\%) eram ingressantes. Trabalhou-se com universitários que frequentavam cursos que compreendiam as áreas de Ciências Humanas e Sociais, Ciências Exatas e Ciências Biológicas, matriculados tanto no período diurno como no noturno.

\section{Instrumento}

A ausência de instrumentos nacionais direcionados à dimensão aqui privilegiada levou à construção de uma escala. Para tanto, foi realizado um levantamento de informações acerca das variáveis a serem analisadas e foram consultados outros instrumentos de pesquisa voltados para o estudante universitário. Para compor os itens da escala realizaram-se entrevistas com dezesseis estudantes universitários. Nestas, a fim de explicitar os comportamentos que representam as interações estabelecidas com os pares, solicitou-se aos estudantes que descrevessem as atividades que desenvolvem com os colegas. Deste conjunto de informações foi elaborada a primeira versão da escala, composta por 50 afirmações.

A análise teórica ocorreu através da verificação de juízes, com o intuito de investigar a adequação da representação comportamental das variáveis analisadas. Solicitou-se a pesquisadores da área que classificassem os itens nos domínios propostos. Dos itens analisados, aqueles que tiveram concordância entre os juízes foram mantidos. Os demais itens foram excluídos ou reescritos, levando-se em consideração as sugestões dos juízes. A escala foi, então, submetida à análise semântica, através da reflexão-falada e na qual estiveram envolvidos 20 universitários. Os itens considerados problemáticos, ou seja, aqueles que geraram dúvidas na leitura/compreensão foram excluídos e/ou reescritos visando a uma melhor elaboração dos mesmos.

Depois de cumpridas as exigências para a elaboração dos instrumentos, a Escala de Interação com os Pares aplicada aos participantes compunha-se por 41 indicadores que deveriam se agrupar em dois domínios: interações acadêmicas e interações sociais. Os itens constituídos por afirmações sobre as interações que estabelecem com os colegas eram 
respondidos através de uma escala de freqüência de cinco pontos.

\section{Procedimentos}

A coleta de dados, que ocorreu tanto de maneira individual como coletiva, teve duração média de 20 minutos e foi realizada na própria instituição na qual os estudantes estavam matriculados, sendo eles contatados em diversos ambientes do convívio universitário. A realização da pesquisa seguiu os princípios presentes na Resolução 196/96 do Conselho Nacional de Saúde, sendo que a mesma foi submetida à apreciação do Comitê de Ética da Faculdade de Ciências Médicas/UNICAMP e aprovada sob parecer número 547/2007.

Após a coleta dos dados, as informações foram inseridas no programa estatístico informatizado Statistical Package for Social Science (SPSS). Para o trabalho com os missings adotou-se a opção pelo parâmetro Listwise e os casos extremos multivariados foram detectados por meio da medida $D^{2}$ de Mabalanobis. A fim de verificar a dispersão dos dados procedeu-se a análise descritiva dos itens. O estudo das propriedades psicométricas da escala incluiu evidências de validade do construto e foi realizado através da Análise Fatorial e consistência interna. Apresenta-se a opção por denominar evidências de validade devido à fase inicial e exploratória de análise do instrumento. Para a realização das análises a amostra de 1070 participantes foi aleatoriamente dividida em dois grupos de 535 participantes cada, sendo os dados do primeiro grupo submetidos à Análise Fatorial Exploratória e, os do segundo grupo, ao estudo confirmatório da estrutura fatorial. A realização da Análise Fatorial Exploratória ocorreu através do método de análise de componentes principais, utilizando-se para extração de fatores a rotação oblíqua (Promax). A estrutura fatorial resultante foi submetida à análise fatorial confirmatória, a fim de confirmar o modelo proposto. Com relação à Análise Fatorial Confirmatória os dados foram tratados no programa PRELIS ${ }^{\circledR}$ versão 2.71. Conforme sugestão de Foguet e Gallart (2000) e Jöreskog e Sörbom (1993), para o trabalho com dados ordinais calcularam-se as matrizes de correlações policóricas e assintóticas de covariância das variáveis que compõem o instrumento. Após a geração das matrizes, as análises dos dados foram realizadas através do programa LISRELSIMPLES versão 8.71 (Jöreskog \& Sörbom, 1993), utilizando-se o método de estimação dos Mínimos Quadrados Ponderados Diagonalizados (DWLS), sugerido na literatura para o trabalho com dados ordinais (Jöreskog, 2005). Posteriormente, para o teste da identidade do modelo e ajuste dos dados ao mesmo foram considerados os resultados da significância estatística do teste Qui-Quadrado, além dos indicadores: Goodness of fit index (GFI), Adjusted goodness of fit index (AGFI), Comparative goodness fit index (CFI), e $\mathrm{O}$ Root mean square error of aproximations (RMSEA). Também levou-se em consideração os coeficientes de regressão estandardizados de cada item junto ao fator, denominado por peso Beta. Para a análise da consistência interna utilizou-se o alpha de Cronbach, indicado para a análise da fidedignidade das dimensões avaliadas.

\section{Resultados e Discussão}

Pela análise descritiva das respostas constatouse que apenas um item - Frequento grupos ou eventos religiosos com outros estudantes - apresentou uma pequena dispersão dos resultados e alta concentração em uma opção de resposta, o que levou à exclusão do mesmo nas análises subsequentes. Após a divisão da amostra em dois grupos, a verificação da possibilidade de realização da análise fatorial ocorreu através do teste de Esfericidade de Bartlett, o qual apresentou resultados satisfatórios para as duas amostras $\left(\chi^{2}=9280,54\right.$; $\left.p<0,001 ; \quad \chi^{2}=9633,13 ; \quad p<0,00\right)$. A medida de adequação de Kaiser-Meyer-Olkin indicou que para ambos os grupos $(\mathrm{KMO}=0,930 ; \mathrm{KMO}=0,929)$ é possível a extração de mais de um fator para os itens que compõem a Escala de Interação com os Pares. A seguir são apresentadas as Análises Fatoriais Exploratória e Confirmatória realizadas com a escala.

Com a primeira amostra de estudantes buscouse identificar, através da Análise dos Componentes Principais, o número de componentes a ser extraído a partir da análise fatorial, o que apontou a presença de no máximo oito fatores, pelo critério de normalização de Kaiser, que apresentam eigenvalue maiores do que 1 (um). Esses oito fatores explicam 59,28\% da variância acumulada. Verificou-se que a formação de dois fatores, inicialmente proposta, explicou $37,74 \%$ da variância. Pelo gráfico Scree Plot notou-se a existência de até sete fatores com autovalores à esquerda da quebra da linha, ou seja, antes que o valor de variância única comece a dominar a estrutura de variância comum (Hair Jr., Anderson, Tatham \& Black, 2005).

As análises estatísticas apresentaram a possibilidade de uma estrutura fatorial composta por um número de fatores distintos ao inicialmente previsto, mas sabe-se que a solução fatorial não deve basear-se, exclusivamente, na configuração estatística. É relevante buscar um sentido para os resultados obtidos, a fim de se respeitar os pressupostos teóricos subjacentes ao teste. Assim, a análise do conjunto de informações sugeriu que a configuração proposta com a extração de quatro fatores é aceitável, uma vez que 
cada fator explica no mínimo $4 \%$ da variância simples e os quatro domínios auxiliam na compreensão de $46,73 \%$ da variância acumulada.

Para a análise do agrupamento dos itens a partir de quatro fatores foi utilizado o Método dos Componentes Principais. Foram realizadas rotações ortogonais e oblíquas, com uma proximidade nos resultados, fazendo-se a opção pelo uso da rotação Promax (Kappa 1), já que havia o pressuposto de que os Tabela 1 - Matriz fatorial da escala e precisão dos fatores fatores estivessem correlacionados. Após a geração dos fatores analisou-se a correlação entre os mesmos, sendo que os valores de $r$ situaram-se entre 0,415 a 0,666, todos estatisticamente significantes, o que reafirma a necessidade de utilização do método rotacional oblíquo. A Tabela 1 apresenta a análise da matriz completa do instrumento, com a descrição dos itens que estão presentes em cada fator. Opta-se pela utilização da carga fatorial mínima de 0,40.

\begin{tabular}{|c|c|c|c|c|c|}
\hline$N^{o}$ & Descrição dos itens da Escala de Interação com os pares & Fator 1 & Fator 2 & Fator 3 & Fator 4 \\
\hline 11 & Obtenho ajuda de colegas para a realização de tarefas em... & 0.665 & & & \\
\hline 24 & Aprendo conteúdos relacionados ao curso com colegas & 0.653 & & & \\
\hline 17 & Peço explicações ou ajuda de colegas sobre uma matéria... & 0.648 & & & \\
\hline 10 & Estudo para uma avaliação ou prova com colegas & 0.646 & & & \\
\hline 23 & Troco mensagens eletrônicas com colegas para organizar... & 0.627 & & & \\
\hline 4 & Faço as tarefas e os trabalhos do meu curso com colegas & 0.614 & & & \\
\hline 22 & Estudo com colegas nas suas residências & 0.588 & & & \\
\hline 38 & Trabalho em grupo em atividades para as disciplinas & 0.495 & & & \\
\hline 34 & Relaciono-me socialmente com colegas através de e-mail... & 0.419 & & & \\
\hline 5 & Peço para um colega ler os trabalhos que escrevi para ver... & 0.384 & & & \\
\hline 40 & Convivo com colegas no percurso de ida e volta à ... & 0.375 & & & \\
\hline 12 & Vou a festas e bares com outros estudantes & & 0.700 & & \\
\hline 8 & Saio com amigos e colegas da universidade & & 0.703 & & \\
\hline 27 & Faço atividades esportivas com meus colegas & & 0.669 & & \\
\hline 9 & Assisto a filmes e programas de TV ou ouço música com... & & 0.652 & & \\
\hline 26 & Vou ao cinema com colegas & & 0.648 & & \\
\hline 14 & Almoço ou janto com colegas da universidade & & 0.608 & & \\
\hline 16 & Encontro colegas fora da sala de aula para bate-papos & & 0.563 & 0.414 & \\
\hline 29 & Convivo socialmente com outros estudantes no Diretório... & & 0.499 & & \\
\hline 30 & Trabalho com colegas na realização de um projeto de... & & 0.381 & & \\
\hline 6 & Converso com colegas sobre relacionamentos afetivos & & & 0.729 & \\
\hline 19 & Converso com meus colegas sobre dificuldades pessoais... & & & 0.671 & \\
\hline 28 & Converso com colegas sobre diversos assuntos como... & & & 0.570 & \\
\hline 15 & Ajudo um colega com problemas pessoais & & & 0.564 & \\
\hline 36 & Converso com colegas sobre meus projetos pessoais & & & 0.551 & \\
\hline 18 & Convivo socialmente com colegas que apresentam ... & & & 0.471 & \\
\hline 21 & Converso socialmente com estudantes com idéias ... & & & 0.460 & \\
\hline 20 & Discuto com colegas idéias sobre os trabalhos do meu... & & & 0.456 & 0.454 \\
\hline 39 & Encontro colegas nas cantinas da universidade & & & 0.392 & \\
\hline 13 & Peço aos colegas informações do curso como, datas de ... & & & 0.336 & \\
\hline 2 & Explico matérias para colegas & & & & 0.668 \\
\hline 35 & Forneço aos colegas informações relacionadas ao curso ... & & & & 0.634 \\
\hline 3 & Converso socialmente com colegas sobre temas como:... & & & & 0.591 \\
\hline 7 & Discuto com outros estudantes idéias ou conceitos... & & & & 0.577 \\
\hline 25 & Ensino colegas a utilizar materiais ou equipamentos ... & & & & 0.571 \\
\hline 41 & Oriento meus colegas na realização de suas atividades de... & & & & 0.567 \\
\hline 33 & Converso com colegas sobre uma matéria ou sobre... & & & & 0.520 \\
\hline 32 & Encontro colegas para discutir questões ligadas ao curso... & & & & 0.495 \\
\hline 1 & Freqüento com colegas atividades artísticas, culturais... & & & & 0.478 \\
\hline 37 & Vou aos eventos acadêmicos com colegas & & & & 0.369 \\
\hline
\end{tabular}


Pela observação dos dados apresentados na Tabela 1, seis itens da escala foram excluídos por apresentarem cargas fatoriais menores do que 0,40 . Outros dois itens convergiram, simultaneamente, em dois fatores. Com relação ao item - Encontro colegas fora da sala de aula para bate-papos - optou-se por mantê-lo agrupado junto ao fator com o qual apresentava maior carga fatorial. Já no que se refere ao item - Discuto com colegas idéias sobre os trabalhos do meu curso - devido à proximidade na carga fatorial, decidiu-se por deixá-lo no fator 4, pela maior semelhança com o conteúdo dos itens deste fator.

A análise dos quatro fatores formados sugere uma subdivisão do agrupamento inicialmente proposto. Assim, os itens previstos para se agruparem no domínio interações acadêmicas dividiram-se em dois grupos, sendo que num estão presentes interações que envolvem discussões e oferecimento de ajuda, e no outro, as interações que dizem respeito à colaboração e recebimento de ajuda. Constatou-se que os itens planejados para comporem o fator interações sociais formaram outros dois grupos: o primeiro, denominado por interações íntimas e, o segundo, por interações características do convívio social e formas de lazer.

Contudo, Kline (1994) sugere que, após a descoberta da estrutura de fatores pela análise fatorial exploratória, a mesma deveria ser confirmada, procedimento adotado pelo presente estudo. A segunda parte deste trabalho visa a apresentar tal confirmação, realizada através da análise dos dados da segunda amostra de 535 participantes.

Para a construção do modelo a ser confirmado levou-se em consideração os erros de mensuração dos itens e as especificações entre as dimensões (variáveis latentes) e os itens. O modelo construído foi composto por 34 itens que convergem em quatro variáveis latentes. Para o cálculo do ajuste dos dados a este modelo teórico havia o pressuposto de que as variáveis latentes (fatores) são correlacionadas entre si. Além disso, fixou-se em $(1,0)$ o coeficiente de regressão não estandardizado $(\lambda)$ em um dos itens associado a cada uma das variáveis latentes, concretizando o que Jöreskog e Sörbom (1993) denominam por variável de referência do fator.

A etapa inicial consistiu na verificação dos indicadores de ajustamento global. $\mathrm{O}$ valor do teste de Qui-quadrado para o ajustamento do modelo foi significativo $\left(\chi^{2}=1998,43, p<0,001\right)$. Este dado não é um bom indicativo de ajuste visto que identifica a existência de diferenças estatisticamente significantes entre a matriz prevista e a matriz dos dados analisada, o que pode ser derivado do tamanho da amostra, devido à sensibilidade do Qui-Quadrado a essa variável (Hair Jr. \& cols., 2005). Porém, é importante a análise de outras medidas, em simultâneo, a fim de considerar um bom ajuste do modelo. Outra medida válida foi CFI $(0,962)$. Através deste índice buscou-se investigar o quanto melhor era o ajuste do modelo estimado, levando-se em consideração o modelo nulo. A literatura tem descrito que valores maiores que 0,95 são indicativos de um bom ajustamento ( $\mathrm{Hu} \&$ Bentler, 1998). O GFI $(0,967)$ e o AGFI $(0,962)$ que comparam os resíduos das matrizes de dados observadas e estimadas revelaram um modelo fortemente ajustado, visto que os valores foram maiores que 0,95 .

Observou-se o RMSEA (0,073), que verifica a magnitude da diferença entre duas matrizes de correlação, uma probabilística, envolvendo erro, e outra verdadeira, isenta de erros. $\mathrm{O}$ índice indicou um ajuste adequado do modelo, já que valores inferiores a 0,05 traduzem um bom ajuste e resultados entre 0,05 a 0,08 traduzem erros razoáveis, sendo considerados adequados (Diniz \& Almeida, 2005).

De maneira geral, o modelo encontra-se ajustado, porém, observou-se a existência de resíduos elevados, o que pode ser reflexo da presença de itens redundantes, que por sua vez aumenta a probabilidade de estarem correlacionadas as variâncias-erro de alguns itens. Nesse sentido, a partir do mesmo modelo iniciou-se um processo de reespecificação e análise a fim de verificar a existência de itens redundantes, os quais, se necessário, seriam excluídos ou inseridas covariâncias entre os erros de mensuração de cada item.

Porém, tomou-se cuidado ao realizar as alterações a fim de evitar a melhora com base simplesmente no acaso (Diniz \& Almeida, 2005). A partir da análise dos índices de modificação e da matriz de covariância de resíduos estandardizados buscou-se que as reespecificações fossem possíveis de serem interpretadas. Neste processo de mudanças do modelo, inicialmente buscou-se excluir itens com baixa carga fatorial e itens cujo erro de mensuração se correlacionava com o de outros. Só no final do processo estimaram-se covariâncias de erro que pudessem ser justificáveis. Destaca-se que a reespecificação do modelo, principalmente através da identificação de correlações entre os erros de mensuração, pautou-se nos conhecimentos teóricos que embasaram a construção do instrumento, visto que não foram realizadas investigações empíricas anteriores com a escala. Em síntese, as modificações assumidas foram alvo de reflexão e somente realizaram-se aquelas que se justificaram do ponto de vista teórico (Byrne, 1998). Destaca-se que em todas essas alterações não foram propostas mudanças na estrutura original do modelo, apenas optou-se por eliminar alguns itens ou estabeler covariâncias entres os indicadores, mantendoos junto às variáveis latentes originalmente previstas. 
Cada uma das modificações foi introduzida separadamente. Ao todo foram realizadas 10 alterações, resultando na exclusão de oito itens e na inclusão de duas covariâncias entre os erros de itens.

Ao finalizar as modificações, o RMSEA atingiu valores amplamente aceitáveis $(0,060)$ dentro da Psicologia, estando abaixo do valor limite $(0,08)$. Os demais indicadores de ajuste, que já apresentavam valores bons, após as alterações também foram melhorados, sendo que os valores de CFI $(0,978)$, GFI $(0,980)$ e AGFI $(0,976)$ indicam um ajuste muito bom dos dados ao modelo. Houve uma diminuição nos resíduos (-3,58 e 4,38), que estiveram próximos aos valores referencias de 2,58.

Após a Análise Fatorial Confirmatória, a Escala de Interação com os Pares ficou constituída por 28 itens, agrupados em quatro fatores, descritos na Tabela 2.

Tabela 2 - Carga Fatorial dos itens que compõem os fatores da escala e índice de consistência interna

\begin{tabular}{|c|c|c|c|}
\hline Fator & $\mathbf{N}^{\mathbf{o}}$ do item & Itens & Carga Fatorial \\
\hline \multirow{7}{*}{$\begin{array}{l}\text { Interações } \\
\text { acadêmicas } \\
\text { discussão e } \\
\text { oferecimento } \\
\text { de auxílio }\end{array}$} & 35 & $\begin{array}{l}\text { Forneço aos colegas informações relacionadas ao curso que } \\
\text { realizamos }\end{array}$ & 0,799 \\
\hline & 20 & Discuto com colegas idéias sobre os trabalhos do meu curso & 0,761 \\
\hline & 33 & $\begin{array}{l}\text { Converso com colegas sobre uma matéria ou sobre } \\
\text { acontecimentos do curso }\end{array}$ & 0,742 \\
\hline & 32 & Encontro colegas para discutir questões ligadas ao curso & 0,685 \\
\hline & 25 & $\begin{array}{l}\text { Ensino colega s a utilizar materiais ou equipamentos da } \\
\text { instituição }\end{array}$ & 0,641 \\
\hline & 41 & $\begin{array}{l}\text { Oriento meus colegas na realização de suas atividades de sala } \\
\text { de aula }\end{array}$ & 0,613 \\
\hline & 7 & $\begin{array}{l}\text { Discuto com outros estudantes idéias ou conceitos } \\
\text { apresentados em sala }\end{array}$ & 0,563 \\
\hline \multirow{8}{*}{$\begin{array}{c}\text { Interações } \\
\text { acadêmicas } \\
\text { colaboração } \\
\text { e } \\
\text { recebimento } \\
\text { de auxílio }\end{array}$} & & Alpha de Cronbach $=0,830$ & \\
\hline & 24 & Aprendo conteúdos relacionados ao curso com colegas & 0,760 \\
\hline & 34 & $\begin{array}{l}\text { Relaciono-me socialmente com colegas através de e-mail ou } \\
\text { mensagens instantâneas }\end{array}$ & 0,749 \\
\hline & 23 & $\begin{array}{l}\text { Troco mensagens eletrônicas com colegas para organizar um } \\
\text { trabalho para o curso }\end{array}$ & 0,693 \\
\hline & 17 & $\begin{array}{l}\text { Peço explicações ou ajuda de colegas sobre uma matéria em } \\
\text { que tenho dúvida }\end{array}$ & 0,657 \\
\hline & 38 & Trabalho em grupo em atividades para as disciplinas & 0,637 \\
\hline & 10 & Estudo para uma avaliação ou prova com colegas & 0,635 \\
\hline & 4 & Faço as tarefas e os trabalhos do meu curso com colegas & 0,626 \\
\hline \multirow{8}{*}{$\begin{array}{c}\text { Interações } \\
\text { características } \\
\text { do convívio } \\
\text { social e de } \\
\text { lazer }\end{array}$} & & Alpha de Cronbach $=0,812$ & \\
\hline & 9 & $\begin{array}{l}\text { Assisto a filmes e programas de TV ou ouço música com meus } \\
\text { colegas }\end{array}$ & 0,861 \\
\hline & 8 & Saio com amigos e colegas da universidade & 0,824 \\
\hline & 16 & Encontro colegas fora da sala de aula para bate-papos & 0,807 \\
\hline & 14 & Almoço ou janto com colegas da universidade & 0,799 \\
\hline & 26 & Vou ao cinema com colegas & 0,769 \\
\hline & 27 & Faço atividades esportivas com meus colegas & 0,586 \\
\hline & 29 & $\begin{array}{l}\text { Convivo socialmente com outros estudantes no D.A.; Atléticas } \\
\text { e Associações de Estudantes }\end{array}$ & 0,546 \\
\hline \multirow{7}{*}{$\begin{array}{l}\text { Interações } \\
\text { íntimas }\end{array}$} & & Alpha de Cronbach $=0,843$ & \\
\hline & 36 & Converso com colegas sobre meus projetos pessoais & 0,783 \\
\hline & 28 & $\begin{array}{l}\text { Converso com colegas sobre diversos assuntos como } \\
\text { acontecimentos atuais, viagens e lazer }\end{array}$ & 0,719 \\
\hline & 15 & Ajudo um colega com problemas pessoais & 0,713 \\
\hline & 6 & Converso com colegas sobre relacionamentos afetivos & 0,696 \\
\hline & 21 & $\begin{array}{l}\text { Converso socialmente com estudantes com idéias diferentes } \\
\text { das minhas }\end{array}$ & 0,582 \\
\hline & & Alpha de Cronbach $=0,786$ & \\
\hline
\end{tabular}


Em síntese, o resultado da análise fatorial confirmatória indicou o ajuste dos dados ao modelo no qual os itens da Escala de Interação com os Pares convergem em quatro fatores que são: Interações que envolvem discussão e oferecimento de auxílio, Interações com ênfase em colaboração e recebimento de auxílio, Interações características do convívio social e formas de lazer e Interações íntimas. É importante observar que todos os fatores apresentam coeficientes de consistência interna adequados, assim como revelou uma consistência interna boa $(0,921)$ o alpha de Cronbach da escala na sua totalidade.

Dos quatro domínios resultantes das análises fatoriais, constata-se que os universitários interagem com os colegas através de relações que são caracterizadas pela presença da discussão e pelo oferecimento de auxílio aos colegas. Nestas interações, um estudante que geralmente apresenta maiores habilidades ou conhecimentos assume o papel de fornecer suporte para os colegas realizarem as atividades acadêmicas. Isso coincide com a formulação vygotskyana denominada zona de desenvolvimento proximal. Frequentemente os estudantes são capazes de resolver problemas ou aprender quando contam com a ajuda de semelhantes, sendo que não disporiam do mesmo desempenho caso realizassem a tarefa sozinhos (Vygotsky, 2007). Também, as interações que envolvem discussões entre pares criam condições para o estudante vivenciar desafios e conflitos, elementos essenciais para desencadear o processo de construção de novos conhecimentos. As discussões possibilitam ao estudante integrar novas idéias, refletir sobre os conceitos e também realizar a síntese de múltiplas perspectivas, atividades ímpares no processo de construção de conhecimentos (Lundberg, 2007).

Outro fator, denominado interações acadêmicas, que envolvem colaboração e recebimento de ajuda, ilustra que na dinâmica interativa dos estudantes é presente uma busca pelo auxílio de colegas para o enfrentamento das tarefas acadêmicas. O universitário pode solicitar anotações dos colegas, investigar formas de resolução de exercícios ou pedir a resposta de um exercício. A busca pelos colegas para a resolução das dúvidas acadêmicas é frequente nos alunos do ensino superior e Newman (2008) acrescenta que tais interações resultam em benefícios aos estudantes porque combinam aspectos do engajamento social e cognitivo e constituem tanto uma estratégia de estudo como de interação social com outros. Além disso, através de um enfoque mais colaborativo, os estudantes podem interagir com colegas através da realização de tarefas, trabalhos e estudos em grupo. Engstrom e Tinto (2008), ao se referirem à aprendizagem colaborativa entre universitários, pontuam que a ocorrência de tais interações possibilita tanto a aquisição de conhecimentos como de responsabilidades e, ainda, cria condições para uma atuação ativa dos estudantes na aprendizagem.

Outras formas de interação, agrupadas no terceiro fator, são as características do convívio social e do lazer, como sair com colegas da universidade, frequentar o Diretório Acadêmico, Atléticas e Associações de Estudantes, participar de atividades culturais e esportivas. Tais interações, segundo Sluzki (1997), têm como função a companhia social e dizem respeito à realização de atividades conjuntas ou simplesmente estar junto aos colegas.

Finalmente, as interações que compõem o último grupo de interações vividas pelos universitários apresentam um vínculo maior de intimidade e se caracterizam pelo oferecimento de suporte de natureza afetiva e pessoal, além de possibilitarem as trocas interpessoais, pautadas na conversa e discussão sobre diversos assuntos (Sluzki, 1997; Zanini \& cols., 2009). Neste estudo, essas interações são denominadas interações íntimas. Em síntese, o agrupamento dos itens da Escala de Interação com os pares em quatro domínios amplia a compreensão das interações que os estudantes estabelecem com os pares e possibilita um olhar mais discriminativo sobre as características das interações.

\section{Considerações Finais}

O estudo psicométrico do instrumento permite afirmar que a Escala de Interação com os Pares apresenta os requisitos que possibilitam considerá-la como um instrumento adequado e fidedigno. Contudo, é pertinente realizarem-se outros estudos, principalmente com estudantes de ensino superior que apresentam características distintas das apresentadas pelos participantes do presente estudo, a fim de aprimorar os resultados psicométricos da escala. Novos estudos utilizando a escala, a partir do modelo confirmado, poderiam investigar a existência de fatores de segunda ordem junto às variáveis latentes.

Porém, a partir das informações obtidas na Escala de Interações com os Pares e com o intuito de discutir aspectos relacionados aos quatro fatores que compõem o instrumento, pode-se afirmar que a rede social do estudante é extensa e inclui todo o conjunto de vínculos interpessoais do sujeito, como amigos e as relações de trabalho e estudo. As análises sobre tais vínculos são relevantes para se compreender os processos psicossociais de integração do indivíduo a uma dada comunidade, bem como para a promoção do 
bem-estar, o desenvolvimento da identidade $\mathrm{e}$ as transformações psicossociais, como as vivenciadas pelos alunos do ensino superior (Pascarella \& Terenzini, 2005; Sluzki, 1997).

Sabe-se que nos fatores obtidos através do estudo psicométricos estão presentes formas de interação que envolvem os aspectos acadêmicos relacionados ao oferecimento de ajuda ou recebimento de auxílio, e interações características do convívio social e, também, íntimas. Cada um desses conjuntos de interações pode oferecer suporte ao enfrentamento das dificuldades que o estudante vivencia no ensino superior, sendo que estudos dessa natureza tornam-se pertinentes.

Ainda com relação ao conteúdo das interações, Tinto (1997), ao investigar a formação das comunidades de aprendizagem, afirma que são das interações de natureza acadêmica, como as colaborativas, investigadas no presente estudo, que são construídos caminhos para que se manifestem outras formas de interação com o estudante. Então, é do contexto acadêmico formal que se inicia a construção de laços de amizades que possibilitam a vivência de outras formas de interação com os pares. Assim, a análise dos caminhos pelos quais as características e o conteúdo das interações modificam-se no decorrer da vivência universitária contribuirá para uma maior compreensão da dinâmica interativa e do processo de socialização e integração dos alunos ao ensino superior.

A importância das interações na formação do estudante reafirma que a dinâmica interativa, em particular aquelas que envolvem os estudantes com os pares, deve merecer atenção por parte das instituições. Diretrizes e programas de curso podem ser propostos como forma de minimizar barreiras, sejam temporais, resultantes do excesso de atividades individuais $\mathrm{e}$ centralizadas em sala de aula, ou logísticas, como as decorrentes de espaços físicos que inviabilizam ou dificultam o convívio e as interações com os pares, como forma de potencializar os aspectos positivos que são decorrentes das interações. Além disso, também pode-se pensar na viabilização de novas formas de aprendizagem, as quais incorporem os pares, tanto como agentes do processo de ensino, como através de atividades mais colaborativas, como estudos e trabalhos em grupo, para que sejam contextos que favoreçam a ocorrência de interações.

A Escala de Interação com os Pares também auxiliará na identificação do impacto da dimensão interativa sobre os diversos aspectos relacionados ao sucesso acadêmico do estudante, como aprendizagem, desenvolvimento cognitivo e permanência no ensino superior (Pascarella \& Terenzini, 2005; Engstrom \& Tinto, 2008).
Finalmente, torna-se importante e necessária a ampliação de estudos sobre as relações interpessoais dos estudantes de ensino superior. Isto se deve ao fato de que a prática educativa tem dado muita ênfase às interações entre os estudantes e seus professores. Longe de menosprezar as contribuições desta relação, a concepção de que o par é um agente educativo importante reafirma a importância de estudos que se pautem na compreensão da rede social do aluno universitário.

\section{Referências}

Almeida, L. A., Soares, A. P., \& Ferreira, A. G. (2000). Transição e adaptação à

universidade: Apresentação de um questionário de vivências acadêmicas (QVA).

Psicologia, 14, 189-208.

Astin, A. W. (1993). What matters in college? Four critical years revisited. San Francisco: Jossey-Bass Publisher.

Bariani, I. C. D., \& Pavani, R. (2008). Sala de aula na universidade: Espaço de relações

interpessoais e participação acadêmica. Estudos de Psicologia, 25, 67-75.

Byrne, B. (1998). Structural Equation Modeling with lisrel, prelis, and simplis: Basic

concepts, applications and programming.

Hillsdale,NJ:Lawrence Erlbaum Associates.

Carini, R. M., Kuh, G. D., \& Klein, S. P. (2006).

Student engagement and student

learning:testing the linkages. Research in Higher

Education, 47, 1-32.

Chickering, A. W., \& Reisser, L. (1993). Education and identity (2a ed.). San

Francisco: Jossey-Bass Publisher.

Diniz, A. M., \& Almeida, L. S. (2005). Escala de Integração Social no Ensino Superior

(EISES): Metodologia de construção e validação. Análise Psicológica, 23, 461-476.

Engstrom, C., \& Tinto, V. (2008). Learning better together: The impact of learning

communities on persistence of low-income students. Opportunity Matters, 1, 5-21.

Feldman, K. A., \& Newcomb, T. M. (1976). The impact of college on students: An

analysis of four decades of research ( 4 a ed.). San Francisco: Jossey-Bass Publisher.

Ferreira, J. A., Medeiros, M. T., \& Pinheiro, M. R. (1997) A teoria de Chickering e o

estudante do Ensino Superior. Revista Portuguesa de Pedagogia, 31, 39-164.

Fior, C. A., \& Mercuri, E. (2003). Formação universitária: $\mathrm{O}$ impacto das atividades não 
obrigatórias nas mudanças pessoais dos estudantes. Em, E. Mercury \& S. A. J.

Polydoro (Orgs.), Estudante universitário: Características e experiencias de

formação (pp. 129-153). Taubaté, SP: Editora Cabral.

Foguet, J. M. B., \& Gallart, G. C. (2000). Modelos de ecuaciones estructurales. Madrid:

Editoral La Muralla.

Hair Jr., J. F., Anderson, R. E., Tatham, R. L., \& Black, W. C. (2005). Análise

multivariada de dados (5a ed.). Porto Alegre, RS:

Bookman.

Hu, L. T., \& Bentler, P. M. (1998). Fit indices in

covariance structure modeling:

Sensitivity to underparameterized model

misspecification. Psychological

Methods, 3, 424-453.

Jöreskog, K. G., \& Sörbom, D. (1993). LISREL8:

Structural equation modeling with the

SIMPLIS command language. Chicago: Scientific

Software.

Jöreskog, K. G. (2005). Structural equation modeling with

ordinal variables using

LISREL. Recuperado em 03 de abril de 2010 de

http://www.ssicentral.com/lisrel/techdocs/ordinal.pd f.

Kline, P. (1994). An easy guide to factor analysis. New

York: Routledge.

Kuh, G. D. (1995). The other curriculum: out-of-class experiences associated with

student learning and personal development. Journal of

Higher Education, 66, 123-

155.

Lundberg, C. A. (2007). Student involvement and institutional commitment to

diversity as predictors of native American student learning. Journal of College

Student Development, 48, 405-417.

Newman, R. S. (2008). Adaptative and nonadaptative help seeking with peer

harassment: An integrative perspective of coping and self-regulation. Educational

Psychologist, 43, 1-15.
Pascarella, E.T. (1985). College environmental influences on learning and cognitive

development: A critical review and synthesus. Em, J.

C. Smart (Ed.), Higher

Education: Handbook of theory and research, 1. New York: Agathon Press.

Pascarella, E., \& Terenzini, P. T. (2005). How college affects students: $A$ third decade

of research. San Francisco: Jossey-Bass.

Pike, G. R., \& Kuh, G. D. (2006). Relationships among structural diversity, informal

peer interactions and perceptions of campus environment. Review of Higher

Education, 29, 425-450.

Sluzki, C. E. (1997). A rede social na prática sistêmica: Alternativas terapêuticas. São

Paulo: Casa do Psicólogo.

Terenzini, P. T, Pascarella, E. T., \& Blimling, G. S. (1996). Students' out-of-class

experiences and their influence on learning and cognitive development: A literature

review. Journal of College Student Development, 37, 149162.

Tinto, V. (1997). Classrooms as communities: Exploring the educational character of

student persistence. Journal of Higher Education, 68, 599-623.

Vygotsky, L. S. (2007). A formação social da mente. São Paulo: Martins Editora.

Whitt, E., Edison, M., Pascarella, E. T., Nora, A., \& Terenzini, P. T. (1999).

Interactions with peers and objective and selfreported cognitive outcomes across

three years of College. Journal of College Student Development, 40, 61-78.

Zanini, D. S., Verolla-Moura, A., \& Queiroz, I. P. A. R. (2009). Apoio social: Aspectos

da validade de constructo em estudantes universitários. Psicologia em Estudo, 14,

195-202.

Recebido em maio de 2010

Reformulado em outubro de 2010

Aprovado em janeiro de 2011 
Sobre os autores:

Camila Alves Fior é psicóloga, doutora em Educação pela UNICAMP. Atualmente, é docente da PUC-MG, campus Poços de Caldas. Tem experiência na área de Psicologia e Educação, com destaque para o ensino superior, através dos temas: formação universitária, evasão, interação com os pares, formação docente.

Elizabeth Mercuri é psicóloga, doutora em Educação pela UNICAMP. É docente colaboradora da Faculdade de Educação, UNICAMP. Tem experiência na área de Psicologia Educacional com ênfase em ensino superior, atuando principalmente nos seguintes temas: estudante universitário, evasão, graduação e ingressantes.

Leandro S. Almeida é doutor em Psicologia da Educação pela Universidade do Porto e professor catedrático da Universidade do Minho. Investiga nas áreas da cognição e construção e validação de instrumentos. É autor de provas de avaliação cognitiva e instrumentos voltados ao ensino superior. 